\title{
Cell Surface Expression of the 70-kD Component of Ku, a DNA-binding Nuclear Autoantigen
}

Bellur S. Prabhakar, Graham P. Allaway, Javaraiah Srinivasappa, and Abner Louis Notkins

Laboratory of Oral Medicine, National Institute of Dental Research, National Institutes of Health, Bethesda, Maryland 20892

\begin{abstract}
The Ku complex, a heterodimer of 86- and 70-kD proteins, is a nuclear DNA-binding autoantigen. However, hydrophobicity analysis of the deduced amino acid sequence of the $70-\mathrm{kD}$ protein had strongly suggested that this might also be a membrane protein. In the present study, using antibodies to synthetic peptides and a polyclonal antiserum to the purified protein, we show that the 70-kD protein of the $\mathrm{Ku}$ complex is present in isolated plasma membranes of human cells. By indirect immunofluorescence microscopy and fluorescein-activated cell sorting, we demonstrate that this autoantigen is exposed on the cell surface. In addition, we have identified several domains of the protein that are exposed. Our study provides one of the first demonstrations of a eukaryotic, nuclear DNA-binding protein that is also on the cell membrane. Moreover, our results might help explain how autoantibodies to the $\mathrm{Ku}$ autoantigen could target cells for an autoimmune attack. (J. Clin. Invest. 1990. 86:1301-1305.) Key words: nuclear autoantigen • cell surface expression - DNA binding protein $\bullet \mathrm{Ku}$ protein
\end{abstract}

\section{Introduction}

Many autoimmune diseases are characterized by the presence of autoantibodies to nuclear proteins. However, it is not clear how these "hidden" antigens could become targets for autoimmune attack. Recently, we cloned and expressed a human cDNA encoding a $70-\mathrm{kD}$ nuclear protein and showed that patients with autoimmune Graves' disease have autoantibodies to this protein $(1,2)$. Independently, Reeves and Sthoeger (3) cloned a cDNA encoding the same protein and showed that it is a component of the $\mathrm{Ku}$ complex. The $\mathrm{Ku}$ complex consists of the 70- and an 86-kD protein (4-8). Earlier studies showed that some patients with SLE and scleroderma polymyositis have antibodies to the Ku complex $(4,9)$. Furthermore, it had been demonstrated that the Ku complex binds DNA, and this binding is mediated by the $70-\mathrm{kD}$ component (5). These observations were confirmed and extended using the recombinant 70-kD protein expressed in the baculovirus system (2). However, hydrophobicity analysis of the amino acid sequence deduced from the cDNA sequence had revealed several potential membrane spanning domains, strongly suggesting that this protein might be membrane associated (1). The present studies

Address reprint requests to Dr. Bellur S. Prabhakar, Laboratory of Oral Medicine, National Institute of Dental Research, National Institutes of Health, Bethesda, MD 20892.

Received for publication 12 December 1989 and in revised form 18 April 1990.

The Journal of Clinical Investigation, Inc

Volume 86, October 1990, 1301-1305 were initiated to investigate whether the protein is also expressed on the plasma membrane.

\section{Methods}

Peptides and antipeptide antibodies. In general, peptides were selected for high solubility, based on the presence of several charged amino acids. Peptides were synthesized according to the deduced amino acid sequence of the 70-kD protein using an automated peptide synthesizer (model 430A; Applied Biosystems, Inc., Foster City, CA). Deprotection and release of the peptides from the resin were done using anhydrous hydrogen fluoride with $10 \%$ anisole at $-5^{\circ} \mathrm{C}$ to $0^{\circ} \mathrm{C}$ for $1-2 \mathrm{~h}$. After ethyl acetate extraction, the peptides were dissolved in $10 \%$ acetic acid, filtered to separate the dissolved peptide from the resin, and the filtrate was lyophilized to give the crude dried peptide. The purity of the peptide was evaluated using HPLC with an aqueous phase of $0.1 \%$ TFA and a mobile phase of $70 \%$ acetonitrile in the aqueous phase. For most analyses done on HPLC, a linear gradient of 0-100\% mobile phase was used over $30 \mathrm{~min}$ at $25^{\circ} \mathrm{C}$ with a C8 reverse-phase HPLC column (The Nest, Southboro, MA). Amino acid analysis was done to verify the correct composition of each peptide (Waters Picotag System; Waters Associates, Milford, MA). Substitutions of A for R, G for Q, S for $L, A$ for $R$, and $A$ for $R$ were noted at residues $165,278,374,444$, and 470 , respectively. Antipeptide hyperimmune sera were prepared by immunizing rabbits with individual peptides coupled to BSA. Peptide-specific antibodies were obtained by affinity chromatography using protein A-Sepharose (Pharmacia Fine Chemicals, Piscataway, NJ) and peptide-specific columns. The individual antipeptide antibodies reacted specifically with the corresponding peptide in an ELISA. These antibodies also reacted well with the $70-\mathrm{kD}$ protein, expressed in insect cells using a recombinant baculovirus, both in Western blots and ELISA.

Western blotting. HeLa cell plasma membrane ghosts were prepared by the method of Brunette and Till (10). The production of recombinant Autographa californica nuclear polyhedrosis virus expressing the $70-\mathrm{kD}$ protein is described elsewhere (2). Samples were run on $10 \%$ SDS-polyacrylamide gels and electroblotted onto nitrocellulose filters. The filters were blocked with buffer containing $5 \%$ nonfat dry milk and $0.1 \%$ Tween-20, then incubated with polyclonal serum to the purified 70-kD component of the Ku autoantigen (purified from MLA 144 monkey leukemia cells by Dr. J. Quinn [National Cancer Institute, National Institutes of Health], manuscript in preparation) diluted 1:500 in the same buffer. After being washed, the bound antibody was detected by incubation with peroxidase-labeled goat antirabbit IgG antibodies (Kirkegaard and Perry Laboratories, Inc., Gaithersburg, MD) at $2.5 \mu \mathrm{g} / \mathrm{ml}$, washed and incubated with chloronaphthol substrate. Alternatively, MAb to proliferating cell nuclear antigen (Boehringer Mannheim Biochemicals, Indianapolis, IN) at 50 $\mu \mathrm{g} / \mathrm{ml}$ was used as the primary antibody, and its binding was detected using peroxidase-labeled goat anti-mouse IgG (Kirkegaard and Perry Laboratories, Inc.) at $10 \mu \mathrm{g} / \mathrm{ml}$.

FACS analysis. All cells were split one day before the analysis and were in log-phase growth. IM9 lymphocytes were grown in suspension culture using RPMI 1640 medium with $10 \%$ FCS. HeLa cells were grown as monolayers in DME with $10 \%$ FCS. HeLa monolayers were rinsed with PBS without calcium and magnesium, then fresh PBS was added and the flasks were placed on ice for $10 \mathrm{~min}$. Cells were dissociated by tapping the flasks. IM9 and HeLa cells were pelleted and 
resuspended in FACS buffer (PBS containing 0.1\% BSA and $0.1 \%$ sodium azide [Sigma Chemical Co., St. Louis, MO]). Cell viability as determined by trypan blue staining was $>95 \%$ (IM9) or $>90 \%$ (HeLa). All incubations were carried out at $4^{\circ} \mathrm{C}$. Cells were incubated with rabbit sera or purified IgG for $1 \mathrm{~h}$ and washed in FACS buffer. The cell pellet was then incubated with FITC-labeled goat anti-rabbit immunoglobulins (Kirkegaard and Perry Laboratories, Inc.) at a dilution of 1:10 for $1 \mathrm{~h}$. The cells were washed with FACS buffer and resuspended in the same buffer containing $0.2 \%$ paraformaldehyde. The cells were analyzed using a FACSCAN (Becton-Dickinson \& Co., Mountain View, CA) analyzer. Most of the dead cells and cell debris were excluded using forward and $90^{\circ}$ scatter analysis.

Immunofluorescence microscopy. HeLa cells were grown as monolayers on glass chamber slides (Lab Tek; Miles Scientific, Naperville, IL). The cells were rinsed in PBS and then fixed in cold acetone/methanol (1:1) for $10 \mathrm{~min}$, air-dried, and stored at $-20^{\circ} \mathrm{C}$ until used. For viable cell staining, HeLa cell monolayers were washed in cold PBS with 5\% FCS to remove any dead cells and stained immediately. The fixed and viable cells were stained at room temperature and $4^{\circ} \mathrm{C}$, respectively. Staining followed the procedure described above for FACS analysis except that the reagents were diluted in PBS with 5\% FCS. The slides were viewed using an Olympus AHBT Microscope with fluorescence attachments.

\section{Results and Discussion}

To study the cellular distribution of the $70-\mathrm{kD}$ protein, we prepared a panel of 12 synthetic peptides and raised polyclonal hyperimmune sera against each peptide. The sequences for the peptides are shown in Table I. Each antipeptide antibody preparations was affinity-purified and was shown to react specifically with the corresponding peptide in an ELISA. The antipeptide antibodies were tested for their reactivity with the 70-kD protein that was expressed using a baculovirus vector (2). All the antipeptide antibodies reacted with the protein by Western blot analysis (Table I).

Initially, we looked for the $70-\mathrm{kD}$ protein in the plasma membrane of HeLa cells using a mixture of antipeptide anti- bodies. In addition, a polyclonal hyperimmune serum to the purified $70-\mathrm{kD}$ protein was used as andependent reagent. HeLa cell plasma membrane ghosts were obtained by the method of Brunette and Till (10), which has been used successfully in a number of studies $(11,12)$. Western blotting showed that the antipeptide antibodies reacted specifically with a single protein of 70-kD in total HeLa cell extracts and in HeLa cell plasma membranes (not shown). An' even stronger reactivity was found when the antiserum to the purified $70-\mathrm{kD}$ protein was used to stain the blots (Fig. 1). The plasma membrane sample (lane $a$ ) was derived from $\sim 50$ times more cells than were used to prepare the total cell extract (lane $b$ ) and yet contained similar quantities of the $70-\mathrm{kD}$ protein. Two methods were used to help exclude the possibility that the membrane preparations had adsorbed nuclear proteins that might be present in the medium. First, the membrane preparations were washed with $0.5 \mathrm{M} \mathrm{NaCl}$ to remove adsorbed proteins. This treatment did not release the $70-\mathrm{kD}$ protein (results not shown). Secondly, the membranes were tested for the presence of another nuclear protein, proliferating cell nuclear antigen. Using an MAb to PCNA, this antigen was found in Western blots of total HeLa extracts but not in HeLa cell membranes (not shown). The plasma membrane-associated 70-kD protein had the same mobility by SDS-polyacrylamide gel electrophoresis as that of the protein derived from total HeLa cell extracts and the recombinant protein (lane $c$ ). These results suggest that the $70-\mathrm{kD}$ protein in the membrane, like the recombinant protein (2), is not glycosylated.

To see whether the protein was exposed on the cell surface, we first stained viable HeLa cells with a mixture of the antipeptide antibodies using indirect immunofluorescence microscopy. In contrast to HeLa cells fixed with acetone/methanol that exhibited primarily nuclear staining (Fig. $2 A$ ), greater than $90 \%$ viable cells showed surface fluorescence (Fig. $2 \mathrm{~B}$ ). No staining was detected using normal rabbit immunoglobulins as a control (not shown). To quantitate this binding we

Table I. Sequences of Synthetic Peptides and Reactivities of Antipeptide Antibodies

\begin{tabular}{|c|c|c|c|c|c|}
\hline \multirow{3}{*}{$\begin{array}{l}\text { Peptide } \\
\text { number }\end{array}$} & \multirow{3}{*}{$\begin{array}{l}\text { Amino acid } \\
\text { numbers }\end{array}$} & \multirow[b]{3}{*}{ Amino acid sequence } & \multicolumn{3}{|c|}{ Reactivity of anti-peptide antibodies with* } \\
\hline & & & \multirow{2}{*}{$\begin{array}{l}\text { 70-kD protein } \\
\text { (by Western blot) }\end{array}$} & \multicolumn{2}{|c|}{$\begin{array}{c}\text { HeLa cells } \\
\text { (by immunofluorescence) }\end{array}$} \\
\hline & & & & Nuclei & Surface \\
\hline 1 & $164-175$ & KAIMLFTNEDNP & + & + & +++ \\
\hline 2 & $185-202$ & RARTKAGDLRDTGIFLDL & $++t$ & +++ & - \\
\hline 3 & $212-228$ & DISLFYRDI ISIAEDED - $\mathrm{NH}_{2}$ & + & - & - \\
\hline 4 & $244-258$ & RKVRAKETRKRALSR & +++ & ++ & + \\
\hline 5 & $270-287$ & SVGIYNLVGKALKPPPIK & ++ & +++ & - \\
\hline 6 & $314-325$ & SDTKRSQIYGSR & ++ & +++ & ++ \\
\hline 7 & $344-358$ & GLMLMGFKPLVLLKK & ++ & +++ & +++ \\
\hline 8 & $365-379$ & SLFVYPEESSVIGSS & + & ++ & +++ \\
\hline 9 & $391-407$ & EKEVAALCRYTPRRNIP & +++ & - & - \\
\hline 11 & $435-452$ & VFLPFADDKAKMPFTEKI & +++ & - & - \\
\hline 12 & $463-480$ & KAIVEKLAFTYRSDSFEN & ++ & - & - \\
\hline
\end{tabular}

* - No reaction; + weak reaction; ++ strong reaction; +++ very strong reaction. The sequence of each synthetic peptide is shown together with the reactivity of the corresponding antipeptide antibody. Viable or fixed (acetone/methanol, 1:1) HeLa cells were stained with antipeptide antibodies and FITC-labeled goat anti-rabbit Ig by indirect immunofluorescence to detect surface and nuclear staining, respectively. 


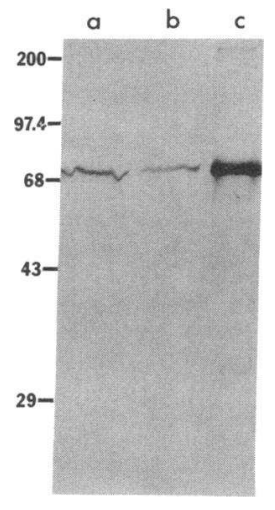

Figure 1. Western blot analysis of HeLa cell extracts: HeLa cell plasma membrane ghosts from $2 \times 10^{6}$ cells $(a)$, HeLa cell extract from $4 \times 10^{4}$ cells $(b)$, and $0.5 \mu \mathrm{g}$ of the 70-kD protein expressed using a recombinant baculovirus vector $(c)$. The blot was probed with antibodies to the $70-\mathrm{kD}$ protein. Molecular masses are in kilodaltons.

stained viable cells with antipeptide antibodies and analyzed them using FACS. The antipeptide antibodies bound to the surface of both HeLa cells (Fig. $2 C$ ) and IM9 cells (a human B lymphoblastoid cell line) (Fig. 2 D). Further support for these observations came from staining viable $\mathrm{HeLa}$ cells with antiserum to the purified $70-\mathrm{kD}$ protein. Fig. $2 E$ shows that this antibody reacted strongly with the HeLa cell surface. The specificity of this reaction was confirmed by the reduction in binding of the serum when preincubated with recombinant $70-\mathrm{kD}$ protein (2) (Fig. $2 F$ ).

To identify regions of the protein expressed on the cell surface, we examined the binding of individual antipeptide antibodies to HeLa cells (Fig. 3). Using FACS, maximal binding was seen with antipeptides $1,7,8$, and 10 . Antipeptides 5 and 6 bound to a lesser degree. The other antipeptide antibodies reacted minimally or not at all with the cell surface. Similar findings were obtained with individual antipeptide antibodies by fluorescence microscopy (Table I). These results demonstrate that several different regions of the protein are exposed. Sequence analysis had shown a number of potential transmembrane domains. One of these domains (amino acid residues 374-390) was of sufficient hydrophobicity to predict that the protein has $>90 \%$ probability of spanning the membrane (1). That exposed domains are found on either side of this hydrophobic region suggests that the protein may traverse the membrane more than once. The lack of reactivity of other antipeptide antibodies suggests that the regions of the protein
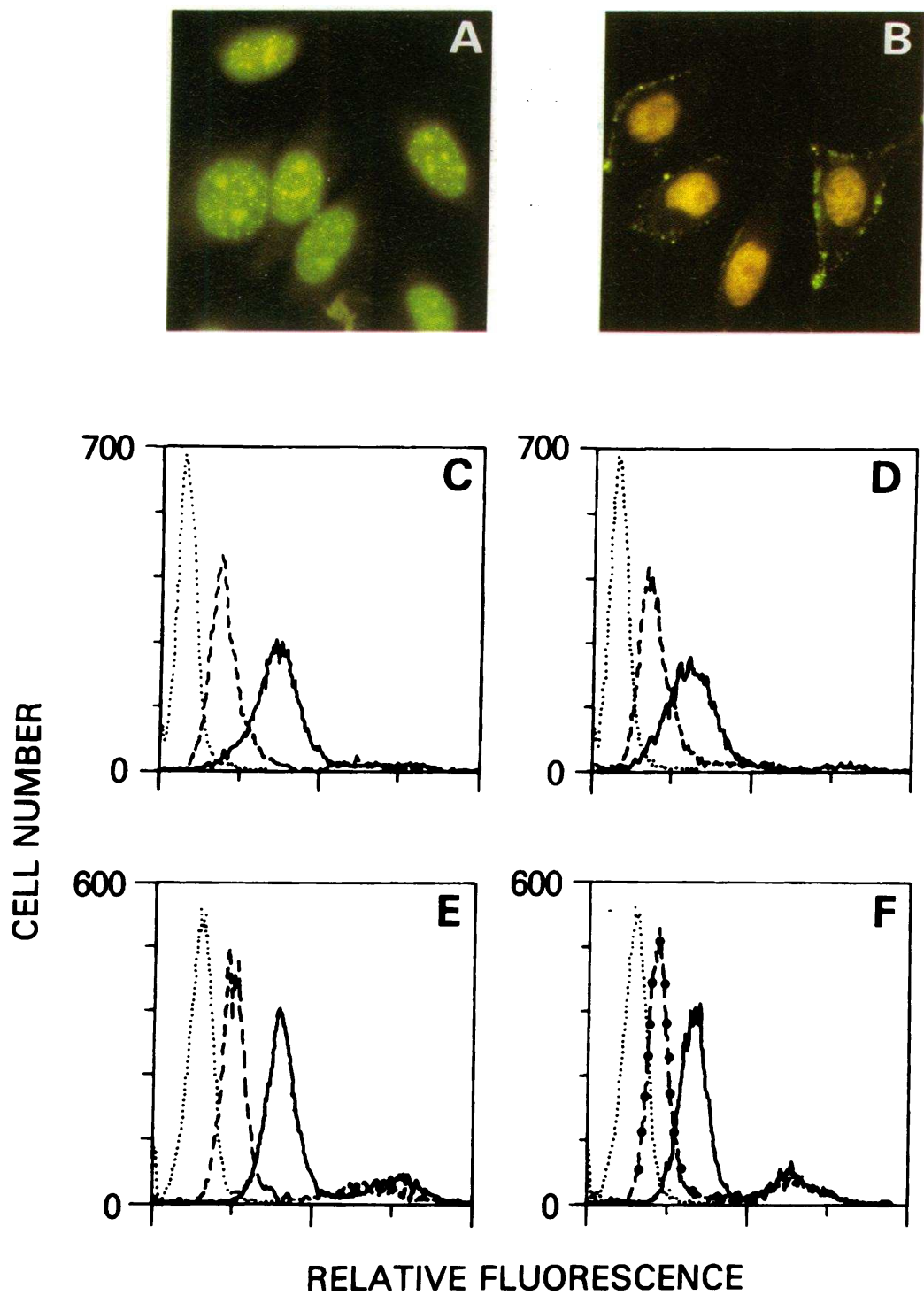

Figure 2. (Top) Indirect immunofluorescence microscopy of HeLa cells with rabbit antipeptide antibodies and fluorescein isothiocyanate-labeled goat anti-rabbit Ig. $(A)$ Nuclear staining of acetone-methanol (1:1) fixed HeLa cells. (B) Viable HeLa cells show specific membrane fluorescence (green), whereas nuclei of these cells show nonspecific autofluorescence (orange/brown). (Bottom) $(C$ and $D)$ show FACS analysis of the binding of a mixture of anti-peptide antibodies to viable $\mathrm{HeLa}$ and IM9 cells, respectively. ( . . ) Cells only; (- - ) normal rabbit Ig; (-) antipeptide antibodies. The reactivity with normal rabbit Ig is very similar to the reactivity found with the second antibody alone (not shown). $E$ shows the binding to viable HeLa cells of the hyperimmune rabbit serum to the $70-\mathrm{kD}$ protein (1:200 dilution). ( $\cdots$ ) Cells only; (- - ) normal rabbit serum (1:200 dilution); ( - ) antisera to the 70 $\mathrm{kDa}$ protein. $F$ shows the inhibition of binding of the antisera by the recombinant $70-\mathrm{kD}$ protein. $(\cdots)$ Cells only; $(\cdot-\cdot \cdot-\cdot \cdot)$ antiserum preincubated with the $70-\mathrm{kD}$ protein; and $(-)$ untreated antiserum. The surface staining procedure was carried out at $4^{\circ} \mathrm{C}$ using PBS containing $0.1 \%$ BSA and $0.1 \%$ sodium azide to prevent capping. 


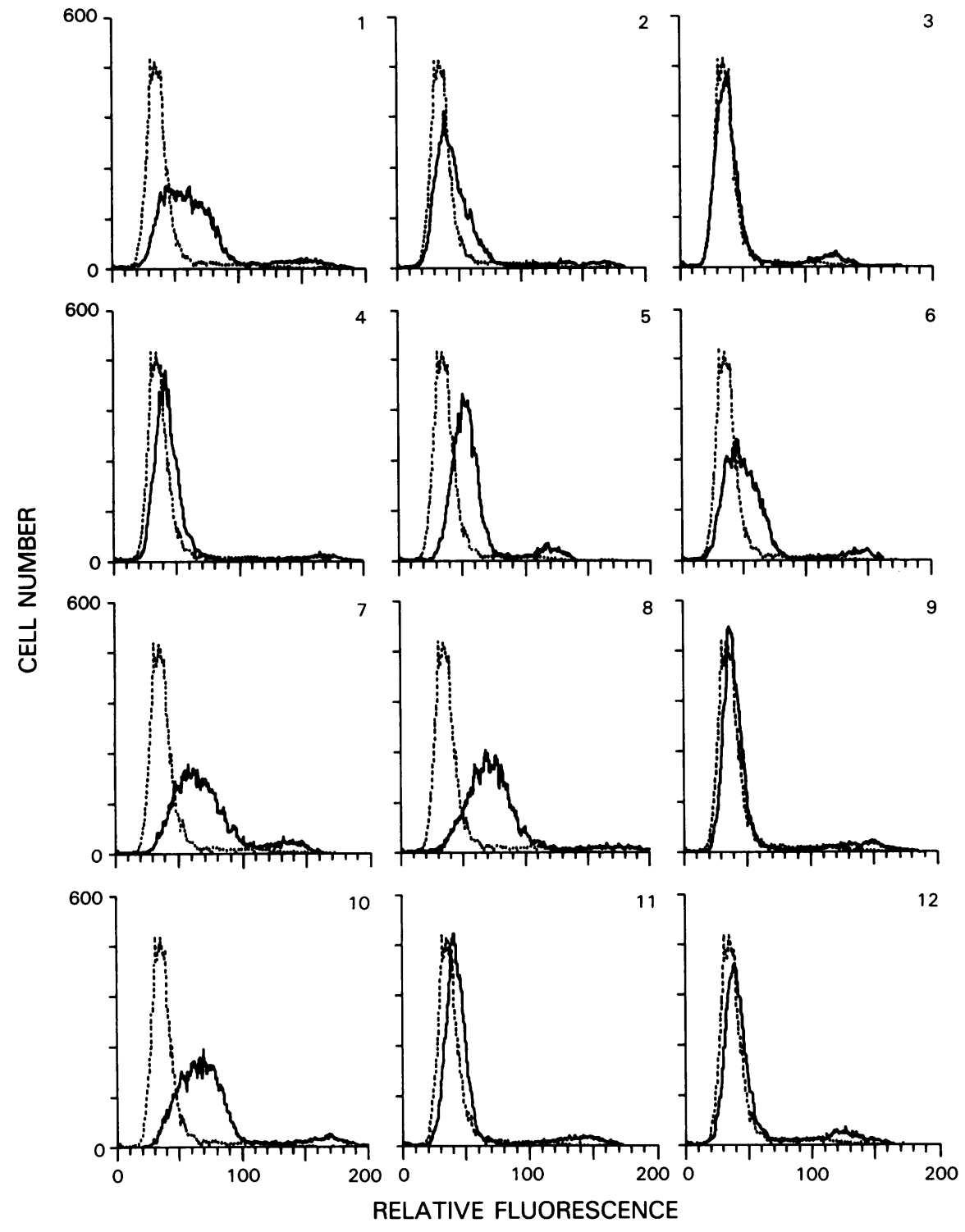

Figure 3. Binding of individual anti-peptide antibodies to HeLa cells: (- - $)$ normal rabbit Ig, (-) anti-peptide antibodies. Numbers 1 through 12 represent antipeptides 1 through 12 , respectively. For staining procedure see legend to Fig. 2. recognized by these antibodies are not exposed on the plasma membrane or are inaccessible to the antibodies due to tertiary conformation of the protein.

The present study clearly demonstrates that the $70-\mathrm{kD}$ protein is present in the plasma membrane of transformed cells and that some epitopes are exposed on the cell surface and are accessible to antibodies. Normal cells express considerable amounts of $\mathrm{Ku}$ proteins. To what extent the $70-\mathrm{kD}$ protein is expressed in the plasma membrane of normal cells and whether there are quantitative differences in its expression in various cell types is yet to be determined. A few DNA-binding proteins of viruses and bacteria have been shown to be associated with the cell membrane. Examples include the originspecific DNA-binding protein of Bacillus subtilis (13) and the SV-40 large T antigen (14). The only known example of such proteins in eukaryotic cells may be the steroid receptors, which bind DNA to exert their action, and are thought to be associated with the plasma membrane (15-17). The function of the $70-\mathrm{kD}$ protein is not known. Whereas previous studies have suggested a role in DNA repair and transposition $(5,6)$, the current results suggest that the protein might be involved in cell signaling, as are those described above.

Earlier, we had found that patients with Graves' disease have autoantibodies against the 70-kD autoantigen $(1,2)$. Other studies have shown that patients with sclerodermapolymyositis and SLE have autoantibodies against the "Ku complex," which consists of the 70-kD protein and an $86-\mathrm{kD}$ protein (4-9). Together, these studies suggest that the 70-kD protein might play a broader role in autoimmunity than previously thought. In this connection it is interesting to note that many other human autoantigens (e.g., Ro, La, Sm, proliferating cell nuclear antigen, nuclear ribonucleoproteins) are nuclear proteins (18). However, it has not been clear how such nuclear antigens, which are apparently inaccessible to the immune system, could be targets of an autoimmune attack. The demonstration that the $70-\mathrm{kD}$ protein is expressed on the cell surface might explain how an autoimmune response to a "nuclear protein" could adversely affect an intact living cell. 


\section{Acknowledgments}

The authors are grateful to Dr. Frank Robey (National Institute of Dental Research, National Institutes of Health [NIH]) for synthesizing the peptides. The authors also thank Dr. John Quinn (National Cancer Institute, $\mathrm{NIH}$ ) for his generosity in supplying the antiserum to the 70-kD protein, Mr. Lloyd Billups for excellent technical help, and Eloise Mange and Karen Hardman for their help in preparing the manuscript.

\section{References}

1. Chan, J. Y. C., M. I. Lerman, B. S. Prabhakar, O. Isozaki, P. Santisteban, R. C. Kuppers, E. L. Oates, A. L. Notkins, and L. D. Kohn. 1989. Cloning and characterization of a cDNA that encodes a 70-kDa novel human thyroid autoantigen. J. Biol. Chem. 264:36513654.

2. Allaway, G. P., A. A. Vivino, L. D. Kohn, A. L. Notkins, B. S. Prabhakar. 1989. Characterization of the $70 \mathrm{kDa}$ component of $\mathrm{Ku}$ autoantigen expressed in insect cell nuclei using a baculovirus vector. Biochem. Biophys. Res. Commun. 168:747-755.

3. Reeves, W. H., and Z. M. Sthoeger. 1989. Molecular cloning of cDNA encoding the p70 $(\mathrm{Ku})$ lupus autoantigen. J. Biol. Chem. 264:5047-5052.

4. Mimori, T., M. Akizuki, H. Yamagata, S. Inada, S. Yoshida, and M. Homma. 1981. Characterization of a high molecular weight acidic nuclear protein recognized by autoantibodies in sera from patients with polymyositis-scleroderma overlap. J. Clin. Invest. 68:611-620.

5. Mimori, T., and J. A. Hardin. 1986. Mechanism of interaction between Ku protein and DNA. J. Biol. Chem. 261:10375-10379.

6. Mimori, T., J. A. Hardin, and J. A. Steitz. 1986. Characterization of the DNA-binding protein antigen $\mathrm{Ku}$ recognized by autoantibodies from patients with rheumatic disorders. J. Biol. Chem. 261:2274-2278.

7. Yaneva, M., and H. Busch. 1986. A 10 S particle released from deoxyribonuclease-sensitive regions of $\mathrm{HeLa}$ cell nuclei contains the 86-kilodalton-70-kilodalton protein complex. Biochemistry. 25:50575064.

8. Yaneva, M., R. Ochs, D. K. McRorie, S. Zweig, and H. Busch. 1986. Purification of an 86-70 kDa nuclear DNA-associated protein complex. Biochim. Biophys. Acta. 841:22-29.

9. Yaneva, M., and F. C. Arnett. 1989. Antibodies against $\mathrm{Ku}$ protein in sera from patients with autoimmune diseases. Clin. Exp. Immunol. 76:366-372.

10. Brunette, D. M., and J. E. Till. 1971. A rapid method for the isolation of L-cell surface membranes using an aqueous two-phase polymer system. J. Membr. Biol. 5:215-224.

11. Weihing, R. R. 1983. Purification of a HeLa cell high molecular weight actin binding protein and its identification in HeLa cell plasma membrane ghosts and intact HeLa cells. Biochemistry. 22:1839-1847.

12. Gruenstein, E., A. Rich, and R. R. Weihing. 1975. Actin associated with membranes from 3T3 mouse fibroblast and HeLa cells. $J$. Cell Biol. 64:223-234.

13. Laffan, J. L., and W. Firshein. 1988. Origin-specific DNA-binding membrane-associated protein may be involved in repression of initiation of DNA replication in Bacillus subtilis. Proc. Natl. Acad. Sci. USA. 85:7452-7456.

14. Butel, J. S., and D. L. Jarvis. 1986. The plasma-membrane-associated form of SV40 large tumor antigen: biochemical and biological properties. Biochim. Biophys. Acta. 865:171-195.

15. Gametchu, B. 1987. Glucocorticoid receptor-like antigen in lymphoma cell membranes: correlation to cell lysis. Science (Wash. DC). 236:456-461.

16. Peck, E. J., J. Burgner, and J. Clark. 1973. Estrophilic binding sites of the uterus. Relation to uptake and retention of estradiol in vitro. Biochemistry. 12:4596-4603.

17. Bression, D., M. Michard, M. L. Dafniet, P. Pagesy, and F. Peillon. 1986. Evidence for a specific estradiol binding site on rat pituitary membranes. Endocrinology. 119:1048-1051.

18. Tan, E. M. 1989. Antinuclear antibodies: Diagnostic markers for autoimmune diseases and probes for cell biology. Adv. Immunol. 44:93-151. 